\title{
A FORMAÇÃO DO “DNA” DIPLOMÁTICO DE SAN MARINO
}

\section{ARTIGO ORIGINAL}

GAZZANEU, Marcelo Sebastiani da Cunha ${ }^{1}$

GAZZANEU, Marcelo Sebastiani da Cunha. A formação do "DNA" diplomático de San Marino. Revista Científica Multidisciplinar Núcleo do Conhecimento. Ano 04, Ed. 12, Vol. 06, pp. 142-156. Dezembro de 2019. ISSN: 2448-0959, Link de acesso: https://www.nucleodoconhecimento.com.br/historia/san-marino

\section{RESUMO}

Dentro do contexto histórico que engloba dominações de povos, extermínios do mesmo, aculturações e perdas de identidade, um enclave em terras italianas transpassa a todas estas intempéries lendariamente desde o ano de 301 e chega, aos dias de hoje, altiva e com o seu bem mais precioso - a liberdade. No entanto, a manutenção da liberdade não foi algo fácil, e, ao longo dos anos, passou a ter uma população numericamente limitada, usando-se de um artifício do mais alto grau de louvor em relação entre povos - a diplomacia. Alianças, apoios, tratados e disputas ao longo de sua existência fizeram que sua arma mais poderosa e mantenedora da estimada liberdade garantisse chegar aos dias de hoje como um caso de sucesso mundial e exemplo para grandes potências. $\mathrm{O}$ aprendizado diplomático, ao longo do tempo, também é algo de se pontuar, pois, de todas as experiências vivenciadas, o melhor posicionamento a se seguir foi a neutralidade diante dos conflitos internacionais, algo que foi admirado e respeitado por grandes potências. Nesse sentido, a pesquisa visa discutir sobre San Marino, pois é uma terra próspera e modelo de liberdade.

Palavras-chave: Liberdade, diplomacia, neutralidade.

1 Graduado em Administração e Pós-Graduação em Relações Internacionais e Diplomacia. 


\section{INTRODUÇÃO}

A história de San Marino vem de frente à realidade existente em seu contexto temporal. Assim, vem ensinar os demais povos que sua política republicana e democrática, sua legislação atemporal e sua forma de se relacionar com os demais povos celebra tratados, acordos, apoios externos e se trata de uma fonte a ser copiada. Contudo, esta realidade não nasce pronta, na verdade se evolui ao longo de seus 1.700 anos de existência. A questão pertinente a esse tema é: como um país de "61,16 km" (SCHEDA PAESE REPUBBLICA DI SAN MARINO, 2017) lendariamente fundado em 301, consegue resistir até os dias de hoje altivo e com pouquíssimas e rápidas invasões, resguardando, sobretudo, a sua liberdade, mantendo relações com países vizinhos? Com esse questionamento temos um objetivo que é mostrar a formação da diplomacia de San Marino ao longo de sua existência e a importância que essa evolução, em relação aos seus vizinhos e outros países aliados, garantiu sua existência até os dias de hoje.

Com isso, a descrição histórica se torna peça fundamental para explicar e entender como tudo começou e se desenrolou até o século XX. Nesse contexto, analisar as posições tomadas, temporalmente, em relação à política externa do país até mesmo com indivíduos que passaram a admirar e manter a liberdade sanmarinense e identificar a as posições tomadas em cada momento histórico para apontar como estas posições foram peças fundamentais para garantir a liberdade são caminhos a serem perseguidos. Para o desenvolvimento desse trabalho, serão apresentados alguns textos e documentos de fontes primárias que o governo de San Marino, na pessoa de seu embaixador, disponibilizou para este trabalho. Também foram utilizados livros históricos bem como foram feitas pesquisas em sites governamentais e não governamentais de San Marino ou sobre esse que corroboraram com o pensamento e a construção cognitiva.

A fim de se realizar a discussão aqui proposta, nesse trabalho será usado o método de pesquisa bibliográfico e documental. Especificamente sobre o caso da pesquisa realizada a partir de documentos Godoy (1995, p. 21) nos aponta que "[...] os documentos normalmente são considerados importantes fontes de dados para outros 
tipos de estudos qualitativos, merecendo, portanto, uma atenção especial." Com isso temos a pesquisa a partir de documentos como fator importante para abordagem da construção de um novo saber, pois é de suma importância a atenção para este tipo de material, pois, uma vez fidedigno, nos alimenta com um saber inigualável. Ao pesquisar uma bibliografia ou documento temos que ter em mente como assim o fazer e Mortatti, et al (2015, p. 13) sana esse questionamento nos dizendo que:

Nessa perspectiva, o que confere singularidade a um texto é o conjunto de aspectos constitutivos de sua configuração. Tais aspectos e as respectivas perguntas a que respondem são relativos às seguintes opções: temático-conteudísticas (o quê?) e estruturais-formais (como?), projetadas por um determinado sujeito (quem?), que se apresenta como um autor de um discurso produzido de determinado ponto de vista e lugar social (de onde?) e momento histórico (quando?), movido por certas necessidades (por quê?), e propósitos (pra quê?), visando a determinado efeito em determinado tipo de leitor (para quem?) e logrando determinado modo de circulação e utilização.

Todo este esforço literal expressa a total admiração pela terra da liberdade e que nos revela um grande caso de sucesso mundial a partir da sua bem como dos seus exemplos diplomáticos.

\section{COMO TUDO COMEÇOU}

San Marino, lendariamente, tem seu início em 301. Sabe-se que um refugiado chamado Marino - da ilha Dalmática chamada Rab - saiu de sua terra devido à perseguição religiosa ou em busca de emprego - em companhia de seu amigo Leo (que, mais tarde, também virara santo) (DELFICO, 1865) e a aventura se estendeu além mar. Sobre isso, Delfico $(1865$, p. 14) nos relata que:

Tal foi que Marino veio mandado a Rimini no quarto século e exercendo o trabalho de pedreiro em obras, então teve a chance de entrar no Monte Titano - uma localidade próxima a Rimini - sempre pronto para administrar materiais para exercer seu trabalho[2] (tradução nossa).

Por ordem do Imperador romano Diocleciano e em virtude de um ataque dos Liburnos, liderado pelo seu rei Demóstenes, no ano de 257, após realizarem um, os colegas conterrâneos se separaram e Marino resolveu viver uma vida de penitência religiosa, 
o que o fez se recolher no Monte Titano - de onde, como pedreiro, extraia pedras para a reconstrução do muro de Rimini (DELFICO, 1865).

Ainda de acordo com a lenda, após uma disputa de terra entre o herdeiro que reclamava o local e uma solicitação de milagre a Marino pela proprietária do Monte, em intercessão do próprio filho reclamante, o ermitão Marino pediu em troca a conversão ao cristianismo de todos os familiares da proprietária do Monte Titano e o próprio monte e assim foi feito por todas as gerações do mesmo e o milagre realizado. Contudo, é fato que alguns elementos históricos não se fazem presente frente a esta narrativa datada do século XII, inclusive a existência do rei Demóstenes dos Liburnos é fantasiosa, pois, alguns historiadores, apontam a presença do Santo nas terras de Titano entre os anos de 500 a 700, mas por uma provável disputa de território com o episcopado de Rimini, essa foi escrita antecipadamente com esse contexto (VALENTINA, 2014).

\subsection{PLACITO FERETRANO}

Em 1749, um homem chamado Annibale degli Abati Olivieri, fez uma grande descoberta nos Arquivos da República de San Marino. Ele encontrou um pergaminho denominado - Placito Feretrano - Zippo (1970, p. 135) nos mostra que "[...] datado em 20 de fevereiro de 885 mostra uma terra sanmarinense completamente liberta de tributos e de servidão de todo tipos [...]" [3] (tradução nossa). O documento se encontrava deteriorado e com 4 linhas ilegíveis, no entanto, o que este achado traz de importante não é sua datação, mas sim o seu conteúdo. Esse documento narrava uma disputa de terras na encosta oeste do Monte Titano que correspondia aos territórios de Casole, Ravellino, Fabrica, Petroniano, Pignaria, Griziano, Erviano, Laritiniano, Silvole e Flagellaria.

Neste contexto, o Bispo de Rimini - Deltone e o Abade do Mosteiro de San Marino Stefano, reclamaram a posse destas terras e coube, nesta disputa "internacional", ao bispo de Montefeltro, acompanhado por quarenta e dois juristas e juízes, a decisão de julgar quem seria o detentor destas terras. Depois de uma acirrada disputa, a decisão final privilegiou o Abade de San Marino. Neste documento é claramente explícita a 
presença de um povo nas terras do Monte Titano, que, então, estava totalmente livre, organizado e contava com uma comunidade agrícola atuante e crescente. Este pergaminho, juntamente com outro documento datado de 951 do Rei da Itália Berengario - que fazia menção ao "povo de San Marino", relata a independência de San Marino perante outros povos que se encontravam ao redor, em especial o bispado de Rimini (VALENTINA, 2017). O texto da Scheda Paese Repubblica di San Marino (2017, p. 3) nos aponta que:

Na realidade na época o território onde se consolidará a sociedade sanmarinense era só um controle político do Papado e do Bispo de Montefeltro. Somente depois da segunda metade do século XIII, em pleno período comum, os sanmarinenses iniciaram um lento processo de libertação deste domínio, criando seu próprio estatuto, magistratura e organização política em grau de gerir autonomamente a coletividade[4] (tradução nossa).

\subsection{O COMEÇO DA DEMOCRACIA}

Com o tempo, a sociedade sanmarinense desenvolveu-se e viu a necessidade de se destacar politicamente nas decisões inerentes ao território. Então, por volta do século XIII, o poder do abade feudal passa para as mãos dos chefes de família e esse grupo passou a ser chamado de Arengo. Essa foi a primeira forma de governo na república, que, ao som do sino da igreja matriz, convocava os membros do Arengo para a reunião. Eles detinham os poderes executivos, legislativos e judiciários. Zippo (1970, p. 135) corrobora com esta ideia e ainda acrescenta:

No final da primeira metade do século XIII, San Marino, que havia visto mais uma vez o crescimento de sua extensão territorial e da própria população, era preciso uma constituição para regular a política local: A máxima autoridade era conferida a dois consules "pró tempore", que exercia seu mandato ao lado do Arengo, isto é, da Assembléia de todos os chefes de família[5] (Tradução nossa).

Os novos empossados a Consules foram os senhores Filippo da Sterpeto e Oddone Scarito que atuaram em um mandato por seis meses a contar de $1^{\circ}$ de outubro de 1244, para evitar, dessa forma, a concentração de poder nas mãos de alguns. Posteriormente, estas figuras foram elevadas ao status de "Capitães" ou "Regentes", 
e, assim, detinham os poderes Executivo e Judiciário. Os membros do Arengo, por sua vez, ficaram com uma espécie de poder proto-legislativo, na medida que criavam regras para o quotidiano dos sanmarinenses (REGGENZA DELLA REPUBBLICA, 2017).

A vontade expansionista de seus, fazia com que a pequena nação tivesse seu crescimento territorial e sua organização como um destaque perante seus vizinhos, que sempre a olhava com o desejo de domínio. Sobre o pontificado do Papa Bonifácio VIII, Zippo (1970, p. 136) nos relata que "[...] os bispos de Ravenna, Rimini e Montefeltro tentaram submeter as rochas do Titano" [6] (tradução nossa). A todo custo cobravam, da livre San Marino, impostos e controle aduaneiro. A população da pequena nação clama, portanto, a intercessão papal. Assim, em uma audiência pública presidida pelo delegado papal, a independência desse país foi assegurada por meio de uma sentença de liberdade desde a época do Santo Fundador. Nesse contexto, quando a população sanmarinense - rural e sem qualquer instrução - foi questionado pelo presidente da audiência sobre o que eles pensavam sobre a questão da liberdade.

Responderam que o homem é livre e não deve ser subordinado a ninguém (VALENTINA, 2014). Durante o século XV houve a necessidade de evolução no então modelo político vigente. Essa evolução parte de um crescimento populacional e da insustentabilidade de chamar um chefe de cada família para formar o governo. Para tanto, resolveu-se eleger sessenta membros para as decisões corriqueiras da vida em comunidade. Esse modelo vigorou até o fim do século XVIII, período no qual a política do micro-país se vê dominada por uma aristocracia instalada no "Conselho Grande e Geral". Essa crise cessou com a invasão Alberoniana. Em 1906 houve uma outra convocação extraordinária do Arengo. Na reunião, 805 chefes das 1054 famílias se fizeram presentes e votaram no novo sistema de governo (VALENTINA, 2014).

\subsection{A EVOLUÇÃO TERRITORIAL E LEGISLATIVA}

Concomitantemente à sua evolução política, San Marino experimentou um aumento de seu território no século XV. Graças às relações diplomáticas com os Duques de 
Urbino, San Marino cresceu durante a guerra de Urbino contra a família Malatesta de Rimini e, em 1462, após os bravos guerreiros de San Marino liderarem e lutarem com as tropas do Estado Pontifício, derrotando os Malatesta, um tratado foi assinado com o Papa. Nesse contexto, San Marino anexou os territórios correspondentes aos atuais: Fiorentino, Montegiardino, Serravalle e, em 1463, anexou Faetano, atingindo, com isso, seu tamanho territorial atual (SCHEDA PAESE REPUBBLICA DI SAN MARINO, 2017).

Um outro fato que acrisola ainda mais a formação do povo livre de San Marino, e neste momento histórico, mais distante da realidade política de seus vizinhos, é a criação de uma constituição - que está em vigor até a atualidade. Giusti (2010/2011, p. 12) vem colocar que "se trata da Leges Statutae Sancti Marini, o Estatuto publicado em 8 de outubro de 1600, cujo são afixados os princípios institucionais e organizacionais da República de San Marino"[7] (tradução nossa), ou seja, regula a política nacional, bem como cerimoniais públicos do país.

\section{TRÊS INVASÕES ESTRANGEIRAS A LIBERDADE}

Apesar de ter obtido sua consolidação política dentro dos arredores do Monte Titano, ainda no século $\mathrm{XVI}$, a pequena nação sofreu, até o século $\mathrm{XIX}$, quatro intervenções estrangeiras, destas, três curtas invasões, apesar de breves, ameaçaram a tão orgulhosa independência de San Marino. No ano de 1503, o filho do Papa Alexandre $\mathrm{VI}$, Cesare Borgia invadiu e ocupou o país por seis meses. Assim, segundo Zippo (1970, p. 136) "a ocupação foi graças a ajuda de um dos castelos [...] se trata de Serravalle, que no primeiro momento não havia aceitado a anexação a San Marino"[8] (tradução nossa). Nesse curto espaço de tempo de ocupação, além de privar a liberdade da população, submetendo-a ao seu Principado de Romagna, mudou a capital para Serravalle. Porém com a ascensão ao trono papal do Cardeal Della Rovere - denominado Papa Júlio II - que, a tempos, era opositor declarado aos atos da família Borgia, os planos expansionistas de Cesare Borgia fracassam e San Marino recuperou sua liberdade. 
Porém, na metade deste século, mais duas outras tentativas de invasões foram investidas contra o pequeno país arquitetados pela corte do Estado Papal que não tolerava um enclave existente no interior de seu Estado, mas ambas as tentativas fracassaram (SCHEDA PAESE REPUBBLICA DI SAN MARINO, 2017). Cem anos depois deste acontecimento com o Príncipe Cesare Borgia, San Marino se vê diplomaticamente ameaçada, pois seu principal aliado estrangeiro, naquele momento, era o Ducado de Urbino. No entanto, o Duque Francisco Maria Della Rovere não possuía herdeiros, o que propiciava a sucessão ao governo de Urbino ao Estado Papal. Frente a esse desafio, a diplomacia sanmarinense, em 1603, antecipou-se aos fatos e assinou, junto ao Papa Clemente III, um tratado de proteção e garantia de independência. Em 1629, o tratado foi confirmado no pontificado de Urbano VIII e posto em vigor a partir de 1631, após a morte do Duque Della Rovere (VALENTINA, 2014).

Apesar de toda a eficiência da diplomacia sanmarinense em garantir a independência de seu país frente aos demais vizinhos que se moldavam a cada troca de seus líderes, invasões e disputas territoriais, o grande desafio ainda estava por vir. No ano de 1739 um cardeal Embaixador do Estado Papal para a Romagna chamado Giulio Alberoni, alegando procurar pelo ex-conselheiro e regente Pietro Lolli e por Marino Belzoppi, considerados proscritos pelo cardeal, avançou com suas tropas armadas para dentro do território de San Marino. Uma vez instalado, o cardeal usurpou o poder desse país, alterou as leis vigentes e obrigou a liderança a jurar lealdade ao Papa. Consequentemente, a diplomacia sanmarinense fez um pedido de socorro ao Vaticano. Assim, o Vaticano enviou o delegado Enrico Enriquez para o país e, em 5 de fevereiro de 1740 , as tropas alberonianas deixaram o país que recuperava a sua independência (CECCHETTI, 2003). O documento da Scheda Paese Repubblica di San Marino $(2017$, p. 3) nos mostra a perspectiva do Estado Papal sobre San Marino:

Na verdade o Estado Pontifício considerava que a liberdade era parcial e fruto de suas exclusivas concessões, tanto que, em 1739, fez uma série de tentativa para por fim na ocupação do pequeno Estado pelo Cardeal Giulio Alberoni. Depois de alguns meses de uma certa submissão, o Papa teve que se render por uma maioria de sanmarinense que não estavam satisfeitas por ter perdido a própria liberdade. Essa 
ocupação também acarretou um mal humor em diversas cortes europeias, as quais, em 5 de fevereiro de 1740, tiveram que oferecer a San Marino a sua antiga independência, sempre, no entanto, sujeita à "proteção e à vigilância" do passado[9] (tradução nossa).

Nos anos de 1795 e 1796, houve uma grande confusão política na França, cuja disputa de poder deixava tanto esse país quanto os estados da península itálica completamente desnorteados. Soares $(2005$, p. 7$)$ relata que:

A instabilidade política também fez parte do cotidiano do autor de $\mathrm{O}$ Príncipe, deixando os Estados italianos fragilizados perante as potências vizinhas, o que o levou a pensar que somente uma autoridade absoluta poderia instaurar a estabilidade política em Florença e nos demais territórios italianos.

Com isso, ao tomar o poder na França, no ano de 1804, Napoleão começa seu projeto expansionista, avançando e conquistando o norte da Itália e se aproximando de San Marino. O país do Monte Titano buscava preservar sua liberdade, porém estava em um grande empasse diplomático, pois poderia tanto celebrar uma aliança com o novo conquistador quanto manter o tratado de anos com o Estado Papal. Nesse contexto, San Marino optou por permanecer neutro até quando pudesse levar essa situação. No avanço das tropas francesas, o napoleônico General Alexandre Berthier enviou uma carta aos Regente. Nela, ordenava a entrega do bispo de Rimini Vincenzo Ferreti por promover e incitar crimes contra os franceses. O não cumprimento dessa ordem poderia resultar na invasão das tropas francesas em terras sanmarinenses.

Coube ao Regente Antonio Onofri responder a missiva, informando que o governo faria o possível para cumprir o pedido, ainda que o bispo pudesse fugir através da fronteira. Com este ato, o Regente Antonio Onofri - aclamado pelos sanmarinenses, por essa ação como "Pai do País" - ganhou respeito e admiração de Napoleão e do Estado Papal. Consequentemente, Napoleão, por meio de uma carta enviada por meio do seu comissário de governo Gasparre Monge, anunciou a confirmação da independência de San Marino e, ainda, ofereceu a oportunidade de expandir seu território por onde ele quisesse alcançar. O governo de San Marino agradeceu o presente, porém, encontrava-se receoso em virtude das futuras revoltas dos "possíveis recém Estados recém-incorporados", e, assim, recusou a oferta de 
expansão e, posteriormente por este ato, passou a não ser considerado como um país aliado da França (VALENTINA, 2014).

\section{A AMIZADE DE GARIBALDI}

Após o fim da expansão napoleônica, em 1815, as terras itálicas estavam repletas de insurreições de movimentos liberais. Esses grupos tinham total apoio por parte de San Marino, que desejava manter sua liberdade. Alguns grupos liberais contavam, inclusive, com o apoio de alguns sanmarinenses. Esses grupos liberais, no entanto, enfrentavam a resistência dos austríacos e do Estado Papal. Por essa pressão externa, em julho de 1849, o governo de San Marino negou o pedido de passagem por suas terras solicitado por Giuseppe Garibaldi, que tinha a intenção de chegar até Veneza e consolidar sua luta pela unificação da Itália. No entanto, após um cerco das tropas austríacas, Garibaldi viu como única saída as terras sanmarinenses. Assim, o General Garibaldi "invadiu” o território do micro-país com seus 1500 homens e chegou ao Palácio Público onde, pessoalmente, realizou a solicitação de asilo ao Regente Domenico Maria Belzoppi.

Este, por sua vez, concedeu o pedido, mas pediu que Garibaldi não envolvesse o país em confronto armado. Em 31 de julho de 1849 Garibaldi e 150 dos seus mais leais homens partiram escondidos para Veneza. Em 2 de agosto do mesmo ano, soldados austríacos invadiram as terras do Monte Titano em busca dos soldados e do próprio Garibaldi (ZIPPO, 1970). Logo após este fato, a Áustria vê a possibilidade de invadir San Marino, tirando sua liberdade. Nesse contexto, San Marino Conseguiu ter sua liberdade preservada, em razão do apoio francês, herança do período de Napoleão Bonaparte, em razão da atuação diplomática desse país. É o que relata o documento da Scheda Paese Repubblica di San Marino (2017, p. 4)

A situação continuava turbulenta também porque San Marino continuava a ser acusado de dar refúgio aos rebeldes. A polêmica durou um longo período, alcançando momentos de debate e de profundo temor pela manutenção da autonomia sanmarinense, porém no a no de 1854 , as autoridades locais conseguiram estabelecer relações diplomáticas com Napoleão III, novo Imperador dos franceses, desejoso de percorrer os passos de seu mais ilustre predecessor[10] (tradução nossa). 
Com isso, o então imperador Napoleão III não permitiu o fim da independência de San Marino pelos austríacos. Garibaldi venceuu a guerra pela unificação italiana e houve o estabelecimento do Reino da Itália em 17 de março de 1861. Nesse contexto, a gratidão de Garibaldi pela ajuda dada em 1849 foi expressa pela não-inclusão de San Marino dentro do plano de unificação italiana. Além disso, San Marino foi elogiada por sua atuação em prol da formação da "nova Itália". Esse ato foi chancelado em 22 de março de 1862, com a assinatura do tratado de respeito recíproco entre os dois países (VALENTINA, 2017).

\section{ANOS DIFÍCEIS E ANOS DE GUERRA}

A liberdade de San Marino, graças às suas forças diplomáticas, estava, mais uma vez, garantida e a paz pairava sobre o Monte Titano. Havia, contudo, crescentes dificuldades na Europa associadas à grande crise econômica gerada pelas economias de base predominante agrícola e à carência de novas estradas, pois, o país, não tinha saída para o mar, ficando em condição desfavorável frente a outros países com litoral. San Marino perdeu muito de seus habitantes em razão da emigração, o que fez famílias inteiras deixarem as terras do Monte Titano em busca de melhores oportunidades tanto na Itália quanto na Alemanha, Áustria, França, Grécia, Argentina, Brasil (uma pequena comunidade no Estado do Espírito Santo), Estados Unidos e Uruguai (VALENTINA, 2014). Apesar das crises e da predominância rural na primeira metade do século XX, San Marino experimentou um período de crescimento econômico, conforme relata o documento da Scheda Paese Repubblica di San Marino (2017, p. 4):

Na primeira metade do século XX, San Marino era ainda uma realidade social predominantemente rural, com uma população composta de pouco mais de 10.000 habitantes, número alcançado entre outro século precedente, porque ao final de setecentos, não eram mais de 3.500 residentes em todo o território. A partir dos anos 60 , sua fisionomia vem mudando radicalmente com o aumento repentino dos residentes, hoje cerca de 32.000, o desenvolvimento das conexões internas e áreas circulantes, do comércio, da indústria e do serviço[11] (tradução nossa). 
No século $X X$, os desafios diplomáticos do país do Santo Dalmático, fundador do país, estavam para serem testados mais uma vez. Apesar de não ter se envolvido, diretamente, na Primeira Guerra Mundial - somente enviando voluntários - San Marino sofreu as consequências desse conflito, com efeitos na economia e, em particular, com o aumento da inflação. Esses efeitos vieram acompanhados de um aumento das desigualdades socioeconômicas, e, o governo da época, mostrava lentidão em criar soluções para sanar essa questão. Quando se cogitou uma solução de cunho social, fatias da classe dominante - receosas de perder seus privilégios começaram a aderir politicamente ao fascismo, que já era dominante na Itália. Após assumir o poder em San Marino, essa corrente de pensamento político garantiu suas benesses e abriam espaço para o fascismo italiano penetrar dentro da nação liberta.

Giannini (http://www.storiaxxisecolo.it/fascismo/fascismo1c.htm) nos relata, em seu texto, que "Como fazia na Itália, Mussolini projetou uma reestruturação do território, como por exemplo, a construção da Ferrovia Rimini-San Marino completamente financiada pela Itália"[12] (tradução nossa). Uma corrente socialista formada externamente entrou no país clandestinamente, ganhou forças e acabou com a tirania fascista que perdurou de 1922 a 1943, quando ocorreu a dissolução do poder dessa (VALENTINA, 2014). No contexto da Segunda Guerra Mundial o desafio de um país indefeso frente a realidade bélica dos demais países poderia causar sua própria destruição, pois, ao assumir um lado dentro desta luta armada, exporia sua vulnerabilidade de proteção, então se optou por criar um Conselho de Estado, composto por vinte membros (inclusive alguns fascistas) e assumir a neutralidade frente a este conflito, com isso, daria mais uma vez a importância de se ter um viés diplomático como a melhor e maior arma em uma batalha de proporções épicas.

A partir daí, San Marino assumiu o compromisso de acolher cerca de cem mil pedidos de asilo e aloja-los da forma que fosse possível dentro de seus limites, apesar da limitação vigente - visto que o país contava, na época, com cerca de quinze mil habitantes, os esforços foram empregues. Contudo, esses esforços foram prejudicados em duas ocasiões: primeiro em 26 de junho de 1944, quando um bombardeio britânico, por um erro de cálculo, atingiu o país, matando sessenta e três 
pessoas e deixando muitos feridos, apesar da intensificação diplomática. Depois desse incidente em mostrar a neutralidade existente nesta terra, o país sofreu, mais uma vez, o embate das tropas britânico-americanas contra os alemães e permanecem até a saída dos refugiados das terras sanmarinenses. Após essa catástrofe mundial, San Marino retomou a normalidade e firmou como lema diplomático a Neutralidade, e o leva altivo em oportunidades e frente aos desafios atuais do mundo vigente (STACCHINI, 2014).

\section{CONCLUSÃO}

San Marino vem ser, sem sombra dúvida, um caso de sucesso para os demais países que se aventuram na diplomacia. São cerca de 1700 anos de experiência frente a diversos desafios ao longo de seu trajeto. Uma pequena população - em grande parte de sua história ruralista - sem um efetivo exército a pronto emprego para lhe socorrer quando mais the precisou, porém, usando, sempre, da inteligência diplomática junto a fortes aliados, e, posteriormente, atuando na neutralidade. Sua formação diplomática não foi ao acaso e sua construção ao longo da história só mostra ao restante dos países que política externa se faz sim à base do diálogo, este diferenciado "DNA" diplomático se torna potencializado perante a diplomacia de outros países por ser único assim. Este trabalho nos apontou que ainda há muito que estudar sobre a história da diplomacia sanmarinense e que ela, ainda nos dias de hoje, com sua política que vem evoluindo de séculos, pode nos mostrar caminhos únicos frente aos desafios vigentes. A busca pela liberdade é incansavelmente bela quando se é feita por meio de um adstrito diálogo.

\section{REFERÊNCIAS}

CECCHETTI, Marino. Alberoni a San Marino: 17-29 ottobre1739. Libertas. 2003. Disponível em: http://www.libertas.sm/libri/Alberoni/Alb_0_1.htm. Acesso em: 02 nov. 2017.

DELFICO, M. Memorie Storiche della Repubblica di San Marino. Tomo I. Napoles: Stabilimento Tipografico del Cav. Caetano Nobile. 1865. Disponível em 
https://books.google.com.br/books?id=vApOAAAAcAAJ\&printsec=frontcover\&hl=pt$B R \&$ source=gbs_ge_summary_r\&cad=0\#v=onepage \&q\&f=false. Acesso em: 01 nov. 2017.

GIANNINI, G. II fascismo a San Marino. Storia XXI Secolo. Disponível em http://www.storiaxxisecolo.it/fascismo/fascismo1c.htm. Acesso em: 15 nov. 2017.

GIUSTI, A. CULTURA, LEGISLAZIONE E MERCATO: una proposta di sviluppo a favore dell'economia della Serenissima Repubblica di San Marino. [2010/2011]. 177 p. Trabalho de Conclusão de Curso (Artes, Patrimonios e Mercados) - LIBERA UNIVERSITA' DI LINGUE E DI COMUNICAZIONE, Milão, 2011.

GODOY, A. S. Pesquisa qualitativa: Tipos fundamentais. Revista de Administração de Empresas, São Paulo, v. 35, n. 3, p. 20-29, maio/jun. 1995.

MORTATTI, M. do. R. L. et al. Sujeitos da história do ensino de leitura e escrita no Brasil. São Paulo: Editora UNESP. 2015.

REGGENZA DELLA REPUBBLICA. Storia. 2017. Disponível em: http://www.reggenzadellarepubblica.sm/on-line/home/la-reggenza/storia.html. Acesso em: 15 nov. 2017.

SCHEDA PAESE REPUBBLICA DI SAN MARINO (Org). Scheda Paese Repubblica di San Marino. San Marino: [s.n.], 2017.

SOARES, D. da. C. Napoleão, o príncipe de Maquiavel: A presença de Maquiavel na formação da imagem pública de Napoleão Bonaparte. 2005. 59 p. Monografia Universidade Federal do Rio Grande do Norte, Natal - RN, 2005.

STACCHINI, A. San Marino 26 giugno 1944: Una scomoda vertà. Borgo Maggiore: Carlo Filippini Editora, 2014.

VALENTINA. Arengo. Sanmarinosite. 25 nov 2014. Disponível em: http://www.sanmarinosite.com/en/history/arengo-forum/. Acesso em: 01 out. 2017. 
. Eighteenth Century and Garibaldi. Sanmarinosite. 07 set 2017. Disponível em: http://www.sanmarinosite.com/en/history/eighteenth-century/. Acesso em: 01 out. 2017.

From XVI to XIX centuty, Napoleon in San Marino. Sanmarinosite. 25 nov 2014. Disponível em: http://www.sanmarinosite.com/en/history/arengo-forum/. Acesso em: 01 out. 2017.

Middle Age. Sanmarinosite. 25 nov 2014. Disponível em: http://www.sanmarinosite.com/en/history/middle-age/. Acesso em: 01 out. 2017.

Origem de San Marino. Sanmarinosite. 21 nov 2014. Disponível em: http://www.sanmarinosite.com/en/history/origins-of-san-marino/. Acesso em: 01 out. 2017.

. Placito Feretrano. Sanmarinosite. 07 set 2017. Disponível em: http://www.sanmarinosite.com/en/history/placito-feretrano/. Acesso em: 01 out. 2017

Statutes of San Marino. Sanmarinosite. 05 set 2017. Disponível em: http://www.sanmarinosite.com/en/history/statutes-san-marino/. Acesso em: 01 out. 2017.

01 out. 2017. The Nineteenth Century. Sanmarinosite. 25 nov 2014. Disponível em: http://www.sanmarinosite.com/en/history/novecento/. Acesso em: 01 out. 2017.

. Word Wars and Fascism in San Marino. 25 nov 2014. Disponível em: http://www.sanmarinosite.com/en/history/world-wars-fascism/. Acesso em: 01 out. 2017.

ZIPPO, I. et al. San Marino leri. Raccolta Rassegna Storica dei Comuni, v. 2, n. 56, p. 132-219, ago/set. 1970. 


\section{ANEXO}

Figura 1: Evolução do território de San Marino em 1463

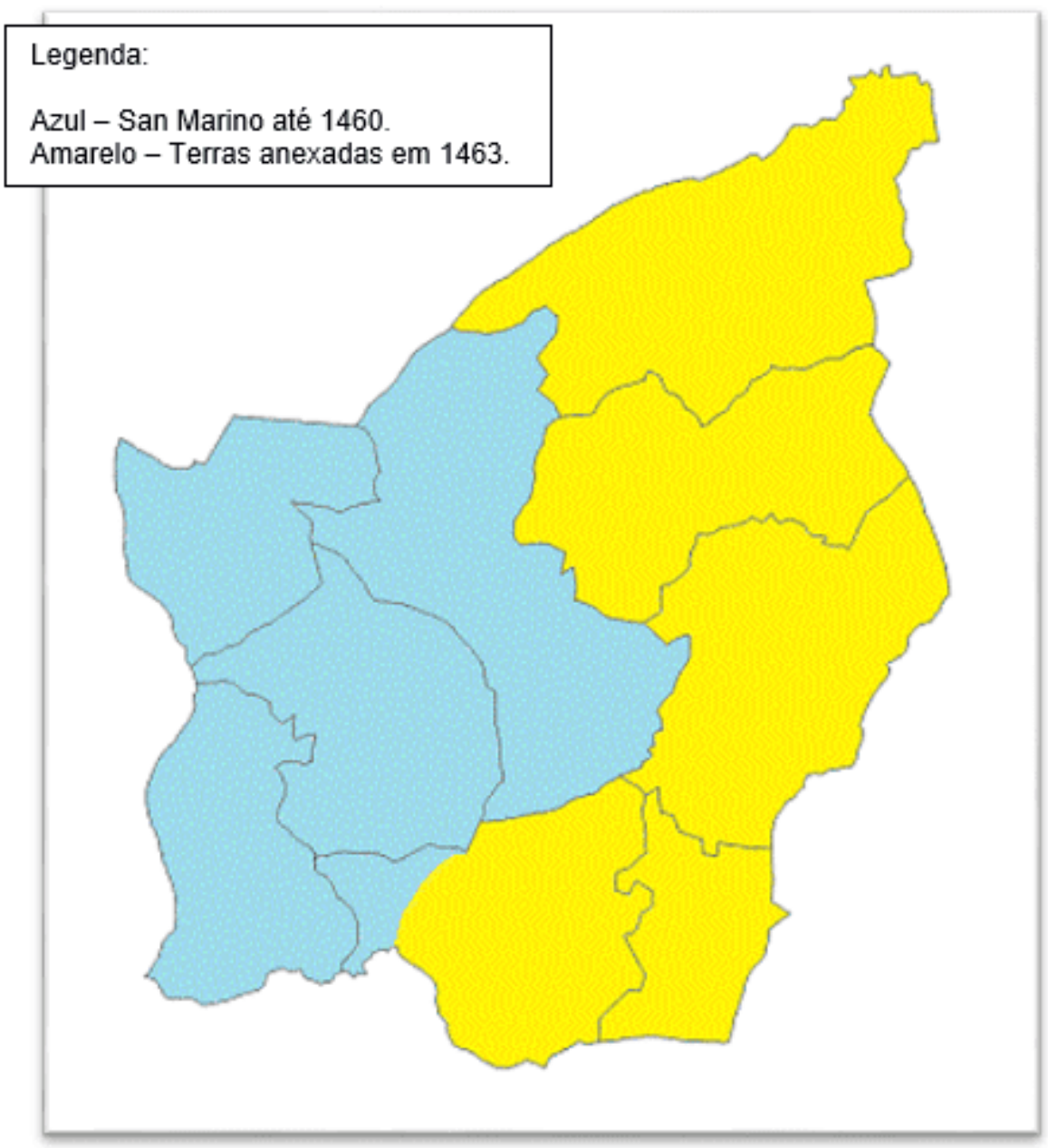

Fonte: Wikipedia

\section{APÊNDICE - REFERÊNCIAS DE NOTA DE RODAPÉ}

2. Tale fu quel Marino venuto o mandato in Rimino dopo la metà del quarto secolo; e essendo o lapidicida di mestiere o dannato a tali opere, ebbe perciò l'occasione di recarsi sul Titano sempre pronto a somministrare materiali per simili lavori.

3. [...] del 20 febbraio 885 , completamente liberada tributi e da servitù di ogni tipo [...] 
4. In realtà all'epoca il territorio su cui si consoliderà la società sammarinese era sotto il controllo politico del Papato e del Vescovo del Montefeltro. Solo dalla seconda metà del XIII secolo, in pieno periodo comunale, i sammarinesi iniziarono un lento processo di liberazione da questo dominio, creando propri statuti, magistrati e organi politici in grado di gestire autonomamente la collettività.

5. Fin dalla prima metà del século XIII San Marino, che aveva visto notevolmente accresciuta la sua estensione territoriale e la prima populazione, si era già data uma costituzione comunale: La massima autorità era conferita a due consuli "pro tempore" i quali esplicavano il próprio mandato affiancati dall' Arengo, cioè dall' assemble adi tutti i capifamiglia.

6. [...] i vescovi di Ravenna, Rimini e Montefeltro tentarono più volte di sottomettere le rocche del Titano.

7. Si tratta delle Leges Statutae Sancti Marini, lo Statutopubblicato I"8 ottobre 1600, in cui sono fissati i principi istituzionali e organizzativi della Repubblica di San Marino.

8. quando Cesare Borgia riucì ad occupare, grazie all' aiuto prestatogli da uno dei Castelli [...] si trata di quello di Serravale che in um primo tempo non aveva gradito l'annessione a San Marino.

9. Infatti lo Stato Pontificio considerava parziale e frutto di sue esclusive concessioni la libertà sammarinese, tanto che nel 1739 attuò un serio tentativo di porvi fine attraverso l'occupazione del piccolo Stato da parte del Cardinale Giulio Alberoni. Dopo alcuni mesi di sottomissione, il Papa si dovette rendere conto, però, che la maggioranza dei Sammarinesi non ammetteva la perdita della propria libertà e che l'occupazione aveva creato malumore in diverse Corti europee, per cui il 5 febbraio 1740 stabilì di ridare a San Marino la sua antica indipendenza, sempre però soggetta alla "protezione" e alla vigilanza del passato.

10. La situazione rimase turbolenta anche dopo perché San Marino continuava ad essere accusato di dare rifugio ai ribelli. La polemica durò a lungo raggiungendo momenti di scontro e di profondo timore per il mantenimento dell'autonomia 
sammarinese, finché nel 1854 le locali autorità riuscirono ad allacciare rapporti diplomatici con Napoleone III, neo imperatore dei francesi, desideroso di emulare e ripercorrere le orme del suo più illustre predecessore.

11. Nella prima metà del $X X$ secolo San Marino era ancora una realtà sociale prevalentemente rurale, con una popolazione composta da poco più di 10.000 abitanti, numero raggiunto tra l'altro solo nel corso del secolo precedente, perché a fine Settecento non vi erano più di 3.500 residenti su tutto il territorio. A partire dagli anni '60, comunque, la sua fisionomia venne a mutarsi radicalmente tramite l'aumento repentino dei residenti, oggi circa 32.000 , lo sviluppo dei collegamenti interni e col circondario, del commercio, dell'industria e dei servizi.

12. Come faceva da tempo in Italia, Mussolini avviò subito progetti di ristrutturazione del territorio, come per esempio la costruzione della ferrovia Rimini- San Marino completamente finanziata dall'Italia.

Enviado: Junho, 2019.

Aprovado: Dezembro, 2019. 